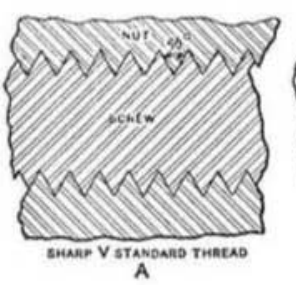

Courtegy of "Machinery"
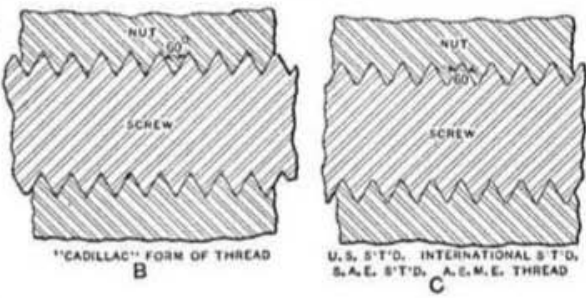
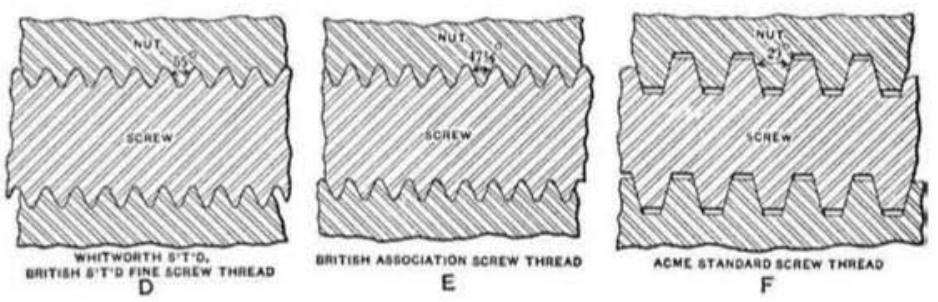

FIG. 1. COMPARATIVE FORMS OF VARIOUS STANDARD SCREW THREADS

\title{
Standards for Screw Threads
}

\section{Can a Universal and International System Be Evolved?

\author{
By Herbert T. Wade
}

$\mathrm{T}$ HE recent war, requiring as it did interchangeability and standardization of military matériel to an extent never before realized, brought distinctly before the civilized nations of the world the importance of international standards. This matter was not settled by the conclusion of the war, but becomes even more important, as a vastly increased international commerce unquestionably will bring to the fore the matter of international commercial standards in many classes of articles and materials. It is inevitable that the markets of the world will be available as never before, and with improved transportation facilities business will come to those that meet the conditions of demand and have their commodities most highly standardized according to some predominant or universal system.

The decision of the United States to avail itself of French and British ordnance and other appliances, as well as manufacture them from their designs, emphasizes the question of standards for various parts, especially screw threads, bolts, nuts, etc., and in the manufacture of vast amounts of equipment by a large number of establishments there was involved securing interchangeability of parts in a marked degree and the use of screw thread systems quite foreign to American mechanical practice.

There was no such thing as a universal or international standard, for in each leading mechanical country of the world, speaking broadly, different standards of screw threads are employed, and in some cases several standards, so that independent of international standards today locally various attempts at standardization have been or are being made. Furthermore the question, while intimately connected with fundamental standards of length, such as those of the AngloSaxon and the International Metric Standards, is at the same time quite apart from them, inasmuch as there are different screw thread standards among the countries using each set of measures, and in some cases several standards in the same country. Consequently it would seem that some approach to a single internantional standard is most desirable so that a reasonable degree of interchangeability in tools and parts con be secured, and it is believed that international commerce, and especially commerce in machinery, machine tools and machine hardware would be promoted by such a policy. If there were any single standard to which all countries might conform, the subject would be comparatively simple; but in every country in the last ten years there have been attempts at greater standardization and more perfect standards and systems. Today there are both national and international commissions investigating this matter, so that a consideration of the various systems now in use based on important work done at the U. S. Bureau of Standards is timely and interesting.

So content are people to take for granted reasonably good or at least serviceable systems of standardization in a single country or in a single industry, that often they are apt to neglect the consideration of earlier conditions and at the same time the necessity for still greater improvements. When it is recalled that a freight car can be coupled in any train on any railway in the United States or Canada, and can at the same time be repaired in any shop, it seems difficult to realize that at one time such a condition of affairs was practically non-existent. Today there is the added incentive to standardization that many of the standards used in single nations intrinsically are subject to improvement, and if they are to be improved it is fair to ask that they should also conform at the same time to other and better standards, and should be applicable throughout the entire civilized world. The task that is before engineers, bureaus of standards, physical laboratories, and like institutions, is most apparent, and engineering commissions with varying objects are now working on this subject.

In all of this work the matter of the screw thread is fundamental, as the screw in one form or other enters into practically all machine design, construction and operation. It must be invariable and readily reproduced with high precision by ordinary commercial shop methods of manufacture. On a standard system of screw thread and sizes naturally depend all bolts, nuts, taps, dies, couplings, and the

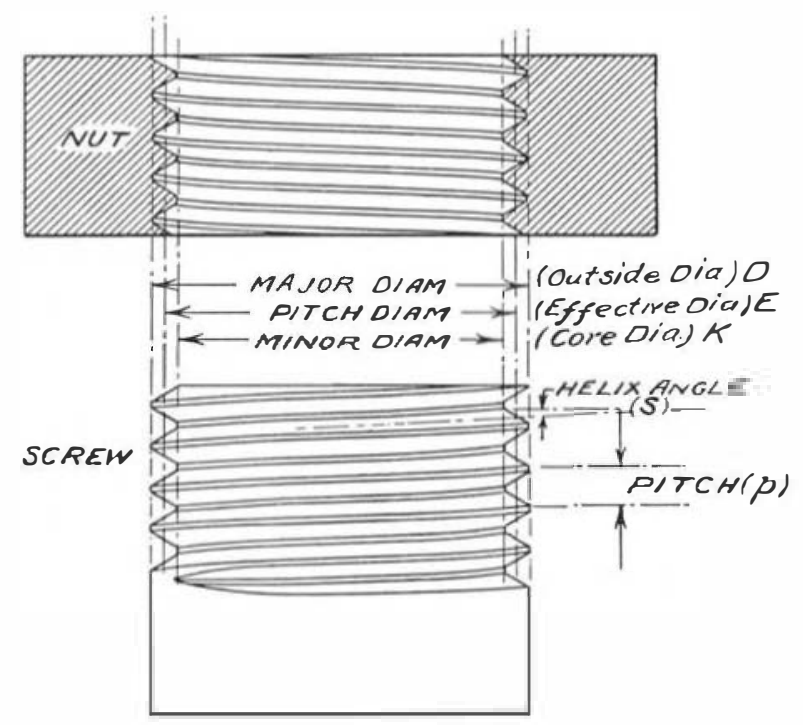

FIG. 2. NUT AND SICREW INDICATING DIAMETERS AS EXPRESSED IN CONVENTIONAL DEFINITIONS

various materials of construction such as pipe which must be purchased in open markets and found within certain limits absolutely interchangeable. In common language they must "fit"; such articles, therefore figure in ordinary 
commerce. Now in any consideration of the question of the screw thread, it is desirable to appreciate the various elements and to understand precisely what is involved, including the very important difference in different systems. The accompanying diagramis, show these elements, and it may be

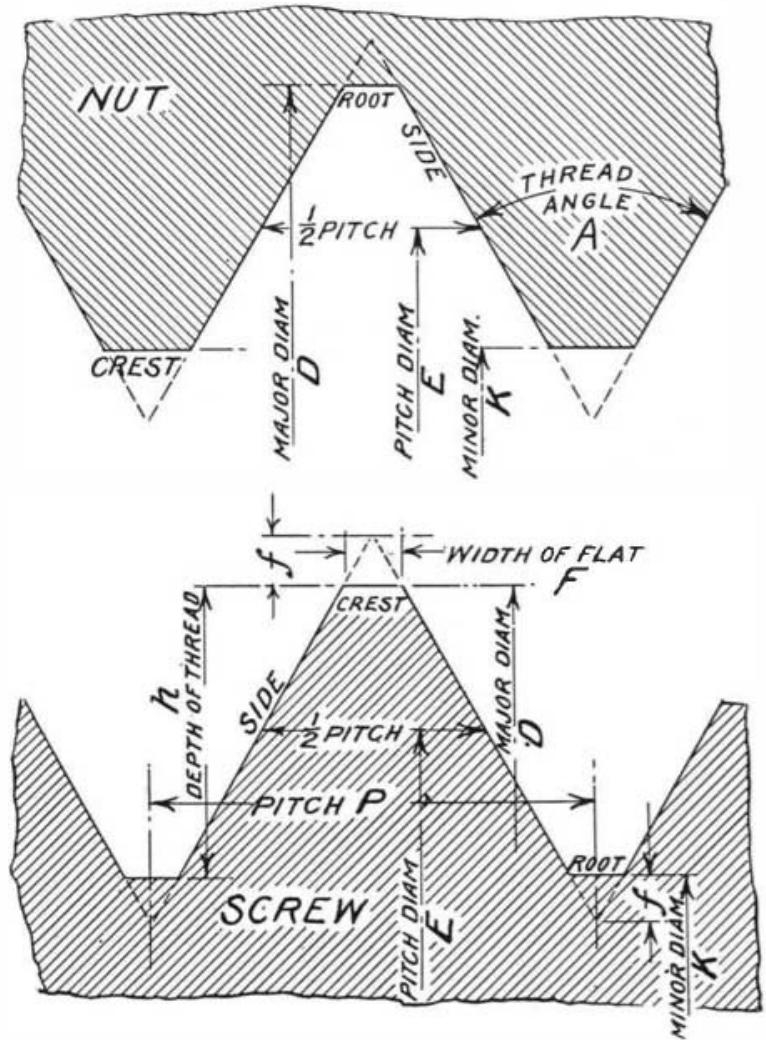

FIG 3. ESISENTIAL ELEMLENTS OF SCREW AND NUT WITH CONVENTIONAL TERMINOLOGY AND SYMBOLS

advantageous to reproduce the definitions applicable as recommended by the United States Bureau of Standards. Considering a screw thread, we can define outside diameter as the diameter on the outside of the thread, in other words, the external or full diameter. In screw thread formulas as used by the U. S. Bureau of Standards, this is indicated by the letter $\mathrm{D}$. The root or core diameter, indicated by $\mathrm{K}$, is the smallest diamoter, whether for a serew or a nut, while the pitch diameter, indicated by $\mathrm{E}$, is defined as the diameter of a screw at a point midway of the depth of the thread equal to the outside diameter, less the depth of one thread, varying in amount for different types of thread. The top or crest of the thread, or flat as it is known in the U. S. Standard Thread, requires no definition, while the root is the bottom surface joining the sides of two adjacent threads, whether in screw or nut. The angle of thread, expressed by $\mathbf{A}$, is the total or included angle between the sides or slopes of a thread in a plane passing through the axis of the screw or nut. The slope of the thread is the angular part which connects the large and small diameters of the thread. The pitch $(\mathrm{P})$ is the distance from a given point on one thread to a similar point on the next thread along the axis of the screw, the distance from center to center of two adjacent threads being taken. In a single thread screw this is sometimes called the lead which is properly however the longitudinal distance traveled by the screw in one turn. The pitch is also the reciprocal of the number of threads (N) per inch or other linear standard. With these terms understood from the definitions and reference to the diagrams, it is possible to consider the various important screw thread systems now in use and show how they differ and how they might be unified in a single system.

Theoretically in order that screws should be interchangeable bath as regards nuts and as regards each other it is necessary that certain of the essential elements named above should be accurate in both screw and nut, but various modifications of a theoretical thread have been made that reduce the number of essential elements where accuracy is necessary for proper fit and interchangeability of screw and nut. For each of the systems described below tolerances either official or more or less accepted in general practice have been worked out and followed to a greater or less extent. In some cases by a slight change as in the diameter of the bolt or nut of certain sizes of screws interchangeability is secured between different systems as the British Whitworth and the U. S. Standard, as illustrated in the accompanying diagram. (Fig. 4.) For various sizes where the pitches are the same the necessary modifications in the effective diameter to secure a satisfactory fit have been calculated.

The British Standard Whitworth Screw Thread was first propose in 1841 by Sir Joseph Whitworth in a paper read before the Institution of Civil Engineers of Great Britain. The aim of this engineer was to represent so far as thread angle, diameters and pitches were concerned the average engineering practice in England at that time. Sir Joseph Whitworth is quoted as saying: "The mean of the angle in 1inch screws was found to be about $55^{\circ}$, which was also nearly the mean in screws of different diameters. Hence it is adopted throughout the scale." The profile of the Whitworth thread, which became standard for Great Britain and wherever British machinery was exported, is shown in the accompanying diagram, and in order to make the accepted practice definitely standard, the British Engineering Standards Committee in 1905 adopted the standiard Whitworth system, and in a report formulated the dimensions of a system. In this report it is stated: "In the Whitworth form of thread the angle between the slopes measured in the axial planes is $55^{\circ}$, the threads are rounded equally at crests and root to a radius of 0.137329 times the pitch, and therefore the depth of the thread is 0.640327 times the pitch." In other words, one-sixth the height of the basic triangle is cut off from the crest of the thread, and one-sixth the height is filled in at the
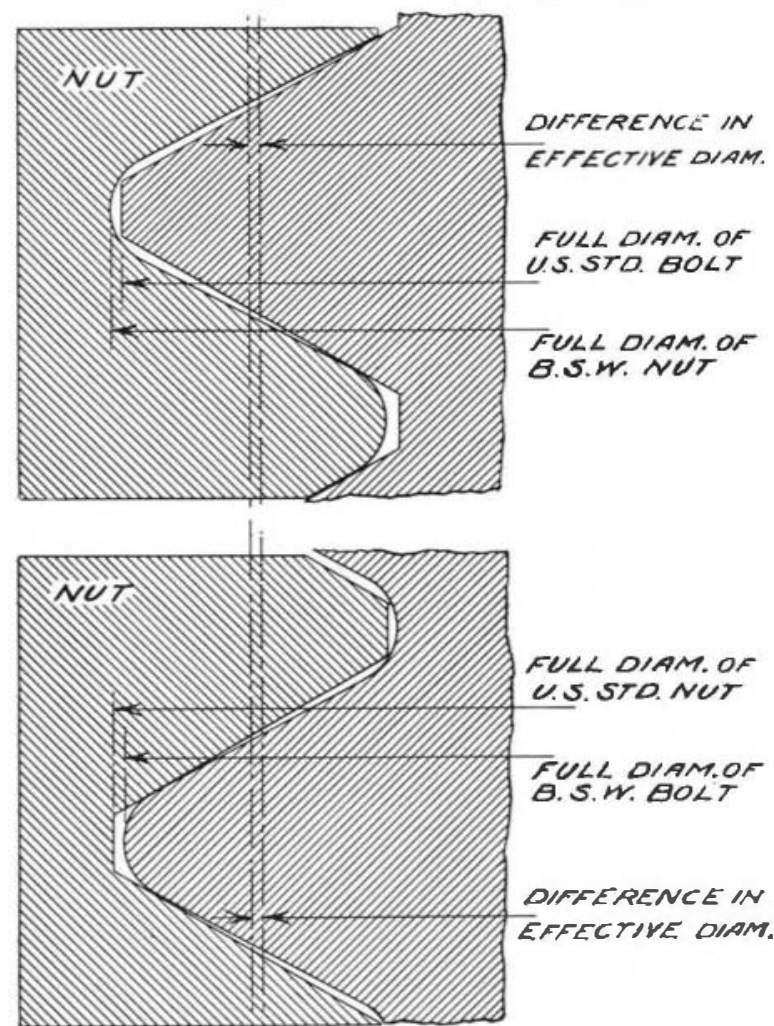

FIG. 4. SEICURING INTERCHANGEABILITY BETWEEN U. S. STANDARD AND BRITISH STANDARD WHITWORTH THREADS

By slightly modifying the effective diameter of either the $U$. S. or the Whitworth bolt or nut in pitches commonl to both systems it is possible to secure interchangeability without modifying the thread form of either. 
WHITWORTH FORM

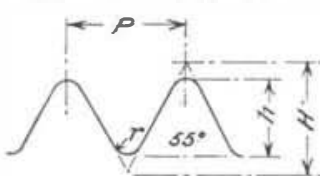

$h=\frac{2}{3} H=0.610327 P$ $T^{*}=0.137329 P$
BRITISH ASSOCIATION FORM

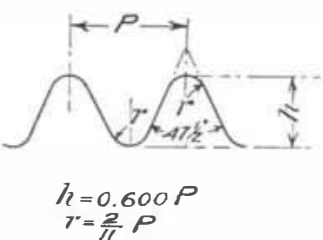

US. STANDARO FORM

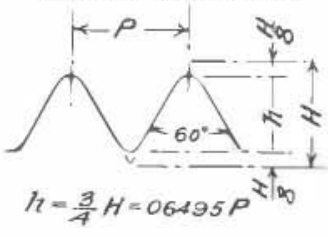

INTERNATIONAL FORM

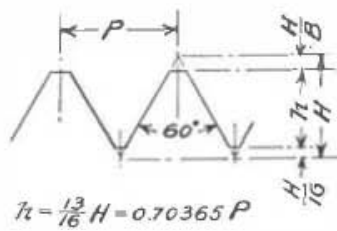

LONENHERZ FORM

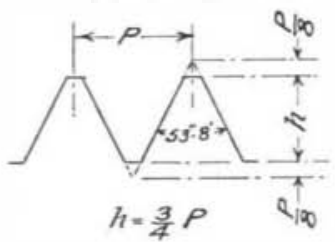

FIG. 5. COMPARISON OF FORMS OF STANDARD THHREADIS

root. On this system the British Engineering Standards Committee has worked out tables of tolerances for bolts and nuts with considerable elaboration. The Whitworth form of thread is employed for the British standard fine screw thread system, for the British standard pipe thread, and the British standard conduit thread.

The British standard fine screw thread system was recommended in 1905 in order to provide a series of fine pitches to supplement the Whitworth series employing the Whitworth form of thread. The pitches recommended are obtained by the formulas $\mathrm{P}=0.1 \times \mathrm{D}^{2 / 3}$ for sizes up to and including 1 inch dilameter, and by formula $\mathrm{P}=0.1 \times \mathrm{D}^{8 / 8}$ for sizes above one inch.

The British standard pipe thread for iron and steel tubes was also adopted in 1905 by the Subcommittee on Screw Threads and linear gages of the British Engineering Standards Commission, and was approved by the main committee in March of that year. Two classes of screw connection were duly recognized by the committee and are now in use, namely, Class 1, the Taper Screw, and Class 2, the Parallel Screw. In Class 1 the screw at the pipe end is tapered 1/16 inch per inch of the length measured on the diameter. The screw in the coupler may be either straight or tapered. Commonly straight coupler and tapered pipe end are used, though conical couplers are used to secure exceptionally good fits. In Class 2 straight screws have the same diameters as the diameters of tapered screws at the gaging notch. The profile of the British Standard Taper Screw for pipe is shown in B of Fig. 8 .

The British standard thread for steel conduit is of the Whitworth form, and as for pipes two classes of steel conduit are recognized as standard: Class A, Plain, and Class B, Screwed. In Class $\mathbf{A}$, which is a light gage conduit, neither the ends of the conduit nor the sockets adjoining the lengths are threaded, but in Class B, which is a heavy gage conduit, both of the ends are threaded with the Whitworth form of thread as defined for British standard pipe threads.
Inasmuch as American mechanical engineers employ the same linear standards as the British, it is desirable next to consider the U. S. Standard Screw Threads, which vary from the Whitworth in many important particulars. This thread was also known as the Franklin Institute or Sellers Thread, from the fact that it was proposed by Mr. William Sellers in a paper read before the Franklin Institute in 1864, and duly approved by a committee of the Institute in Decomber of that year. It was adopted with slight modifications by the United States Navy Department and the Master Mechanics and Car Builders' Association, and it is on this standard that the very widespread standardization found in the United States has been carried on, by a formula where $\mathrm{N}=\frac{16.64}{(15 \mathrm{D}+10)-2}$ ben $=\frac{10.64}{(15+1.0)-2.909}$ where $\mathbf{N}$ equals the number of threads per inch and $\mathrm{D}$ the diameter in inches. As a result of this formula values for $\mathbf{N}$ are given which agree with the Whitworth pitches, except in two or three sizes.

Now referring to the diagram showing the U. S. Standard Screw Threads, the difference between it and the Whitworth is most apparent in the thread angle, where $60^{\circ}$ was selected in place of $55^{\circ}$. Mr. Sellers stated his objections to the $55^{\circ}$ angle as follows :

1. The angle of the $55^{\circ}$ is difficult of verification.

2. The curve at the top and bottom of the screw will not fit the corresponding curve in the nut.

3. The increased costs and complications of cutting tools required to form this kind of thread in the lathe.

The angle of $60^{\circ}$ was selected for two reasons, namely, that it could be reproduced and verified with greater ease, and secondly, because it was also in more general use in the United States. The Sellers system underwent slight modifcations, and then became the United States Standard System, where the thread is flattened $1 / 8$ the height of basic triangle at crest of thread and nominally filled in $1 / 8$ the height at the root. The nominal depth of the thread then is 0.64952 times the pitch as is shown in the diagram Fig. 5.

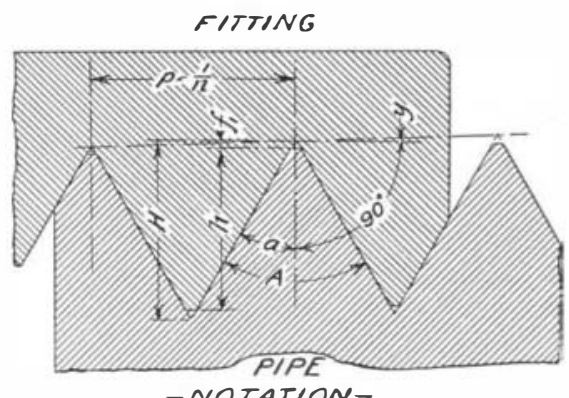

$$
\begin{aligned}
& A=60^{\circ} \quad \text { Angle of Thread } \\
& \text { a }-30^{\circ} \quad \text { Ore-half Angle of Thread } \\
& y=1 " 47^{\prime} \text { approx Taper. Angle }=\frac{1 "}{16} \text { per Incli on Diameter. } \\
& H=0.866025 \rho \quad \text { Depth of } 60^{\circ} \text { Sharp " }{ }^{\prime} \text { 'Thread } \\
& \begin{aligned}
h & =0.800000 \mathrm{p} \\
& =0.823761 \mathrm{H}
\end{aligned} \quad \text { Oepth of Thread an Work } \\
& \begin{aligned}
f_{1} & =0.033012 \mathrm{PH} \\
& =0.038120 \mathrm{H}
\end{aligned} \\
& \begin{array}{l}
=0.038120 \mathrm{H} \\
=0.041266 \mathrm{H} \text { Dept/2 of Truncation }
\end{array} \\
& p=\frac{1}{x} \\
& \text { Pitcll } \\
& \text { Number of Threads per linch }
\end{aligned}
$$

FIG. 6. AMERICAN BRIGGS STANDARD THREAD FORM

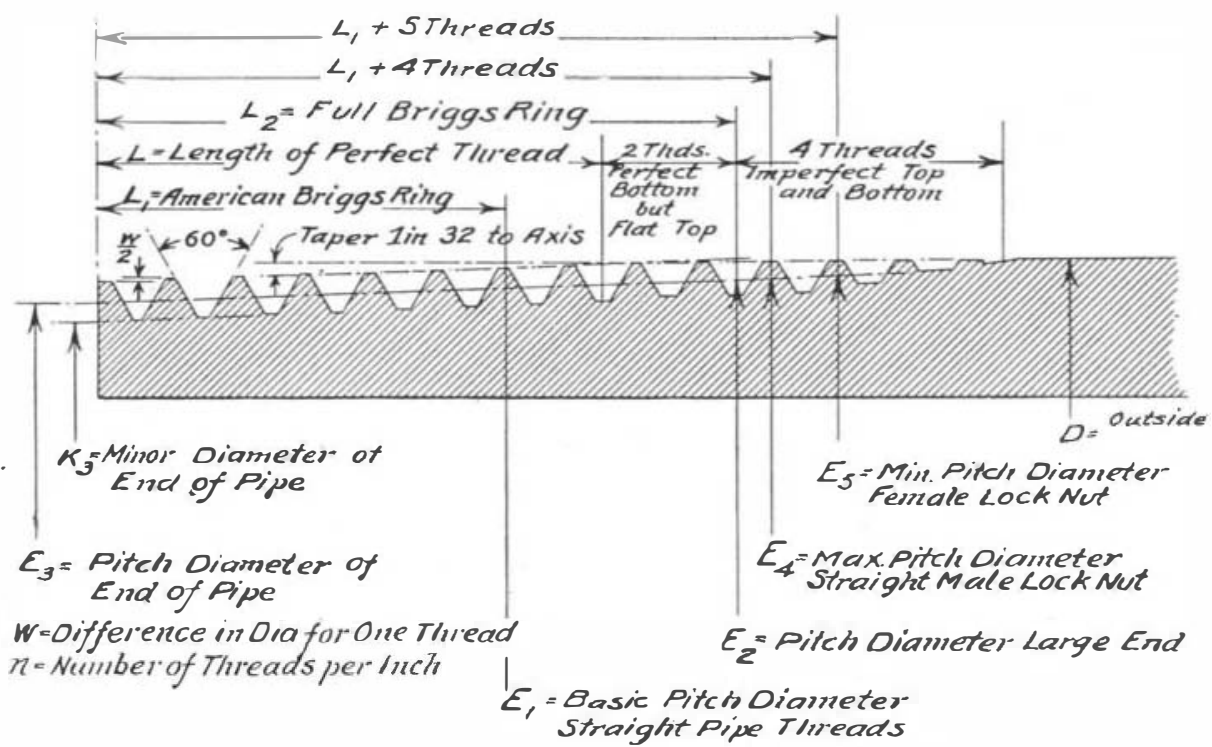

FIG. 7. U. S. NATIONAT TAPER AND STRAIGHT PIPE THREAD 
In the United States the lack of interchangeability of small machine screws gradually became apparent, and in 1902 the American Society of Mechanical Engineers appointed a committee to report on the standard proportions for these screws. This report was duly formulated in 1907, and the committee recommended the A.S.M.E. Machine Screw Standard where the U. S. Standard form of thread was used and the pltches were a function of the diameter as expressed by the formula threads per inch $=\frac{6.5}{\mathrm{D}+0.02}$.

With the development of machine work, and especially in the construction of automobiles, it was found that finer pitch screws were required than had figured in the U. S. Standard system, and accordingly the A.L.A.M. Fine Pitch Screw Thread System was developed for automobile work. In 1911 this system was revised and extended. The finer pitch screws were required for automobile work for two reasons: first, fine pitch screws and nuts not work loose readily when subject to vibration; second, because of increased strength due to increased core diameter obtained, weight could be saved by using smaller screws. Previous objections to using threads of fine pitch that they were easily stripped or crossed in making up did not apply in automobile construction, because it was possible to specify and secure a good fit between nut and screw, and furthermore, it was possible to use a good grade of steel exclusively.

In March, 1918, the Society of Automotive Engineers proposed a system of still finer threads for special automobile work. The automobile industry, on account of the large number of machines manufactured in well equipped and special shops in many cases has employed special screws peculiar to a single manufacturer or organization.

In the United States, while the United States Standar is generally followed, and the 60 degrees angle in the profile, there are various modifications ranging from the sharp $V$ standard, where thread and nut are supposed to fit accurately to special forms used by large manufacturers, examples of which are seen in motor car manufactories. For example, the so-called "Cadillac" form of thread, where the screw thread of the sharp $\mathrm{V}$ standard is modified at the crest, it is only necessary to consider the pitch diameter, pitch and angle of thread on the screw and the nut. These two types are shown in profile in $\mathbf{A}$ and $\mathbf{B}$ of Fig. 1.

The Acme Standard Screw Thread is found in American machine design and takes the place of the square thread, being an adaptation of the form of worm thread commonly employed. It is a little shallower than the worm thread, but the same depth as the square thread, and much stronger than the latter. The Acme thread has a clearance top and bottom, so that the principal consideration involved is the accuracy of the thread as regards the angular faces and its pitch and pitch diameter. The angle of the thread is 29 degrees as is shown in $\mathrm{F}$ of Fig. 1.

The width of point of tool for screw or top thread $=(0.3707$ $\div$ No. of threads per inch) -0.0052 .

The width of screw or nut thread $=0.3707+$ No. of threads per inch.

The diameter of Tap $=$ Diameter of Screw +0.020 .

Diam. of Tap or: $=$ Diam. of Screw $-\frac{1}{\text { No. of Threadsperin }}+0.020$

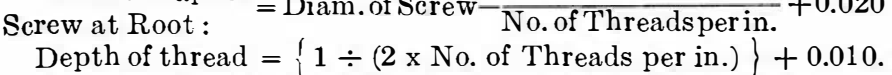

The Briggs Standard form of pipe thread is in common use in the United States and was adopted by the American Society of Mechanical Engineers, whose committee reported, recommending this system in 1886 . The original Briggs Standard pipe thread has an included angle of $60^{\circ}$, and is slightly rounded at the top and bottom, so that the single depth of the thread, instead of being equal to the pitch times 0.866 inch is only $4 / 5$ of the pitch, or equal to the pitch times 0.8 inch. The Briggs Standard is also made in a modified form resembling the U. S. Standard form of thread. The Briggs thread tapers with respect to the axis of 1 part in 32 , or $3 / 4$ of an inch to the foot total taper. It is very obvious that absolute interchangeability obtained through accuracy of threads and standards is necessary in all mechanical and construction work. Pipe of various forms, together with couplings and other parts, must fit to the required degree of accuracy.

An early attempt to secure precision in screw threads was made in 1878, when the Horological Section of the Geneva Society of Arts recommended a system of screw threads designed by Professor M. Thury. This system was based on the metric standard and reproduced the measurement of well proportioned watch and small instrument screws then in actual use in European countries. The thread has an angle of

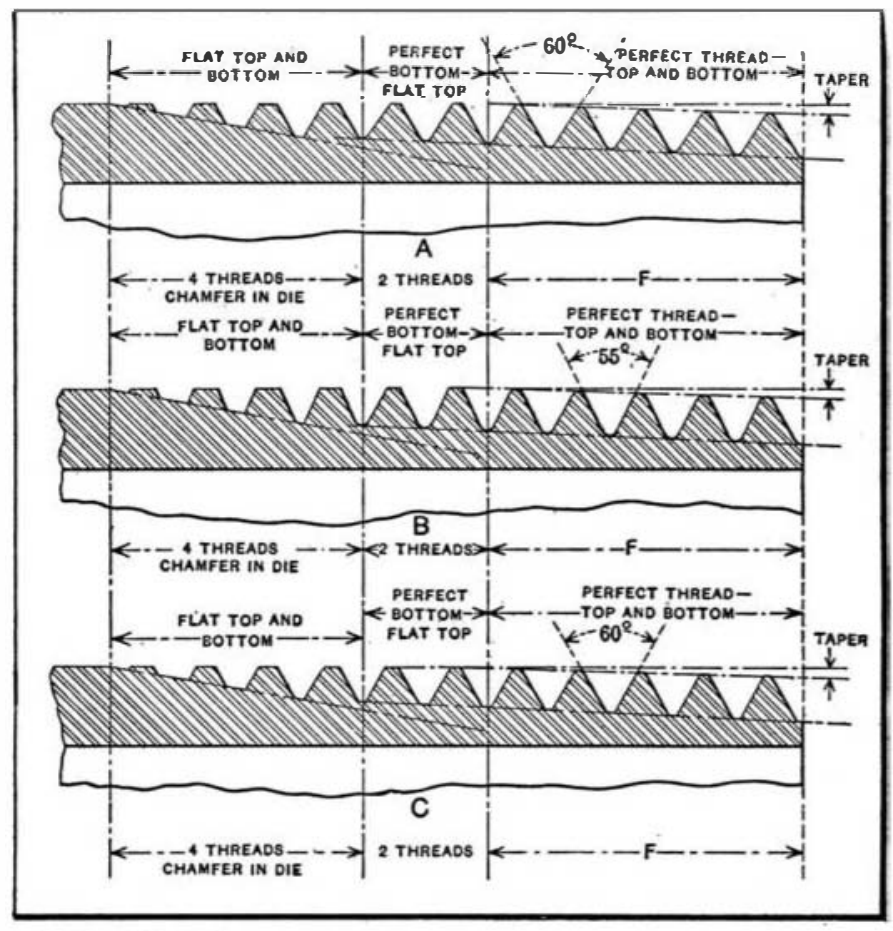

Courtesy of "Machinery".

FIG. 8. AMERICAN BRIGGS (A), BRITISH WHITWORTH (B), AND MODIFIED BRIGGS (C) PIPE THREADS

$471 / 2^{\circ}$, and is rounded at the crest with a radius of $1 / 6 \mathrm{p}$, and at the root with a radius of $1 / 5 \mathrm{P}$, giving a depth of thread of $0.6 \mathrm{P}$. The various sizes were designated by consecutive numbers from No. $0=6 \mathrm{~mm}$. diameter, $1 \mathrm{~mm}$. pitch, to No. 25 , $0.254 \mathrm{~mm}$. diameter, $0.0178 \mathrm{~mm}$. pitch. The pitch corresponding to any size number was expresed by the formula $P=0 . \mathrm{S}^{\mathrm{n}}$. The outside diameter corresponding to any pitch was expressed by the formula $\mathrm{D}=6$ times $\mathrm{P}^{6 / 5}$. In 1884 the British Association for the Advancement of Science recommended the use of the Thury System with modifications for all screws below $1 / 4$ inch in diameter, and this system came into general use, particularly for instruments in scientific work. The modification in the thread form was designed to give equal rounding at crest and root of approximately $2 / 11 \mathrm{P}$. The British Engineering Standards Committee in their 1903 report on British Standard Screw Threads gave dimensions of screw threads in this system, including the recommended clearances between the crests and roots of the threads. This system is of interest, inasmuch as it has indicated the practical use in Great Britain of threads based on the Metric System, and no difficulty has been experienced in their use on small apparatus.

With the development of machine tools made according to the Metric System and the general use of the Metric System by the Continental countries, it was obvious that a metric screw thread standard for the larger sizes of screw threads should be adopted. The French Société d'Encouragement de l'Industrie Nationale in 1894 adopted a metric screw thread sys- 
tem, and this was approved and adopted by an International Congress convened at Zurich in 1898, and representing the principal Continental countries. The profile of the screw thread is shown in Figures 1 and 5.

In both systems the form of thread had a $60^{\circ}$ angle, and the crest of the thread was flattened $1 / 8$ the height of the basic triangle, while the root was filled in 1/16 the height, thus affording a definite clearance between tops and bottoms of threads, and in the main following the profile of the Sellers Thread. The principal difference between the French and the International Systems was in the pitch of the 8,9 , and $12 \mathrm{~mm}$. screws the French specifying $1 \mathrm{~mm}$. and $1.5 \mathrm{~mm}$. pitch respectively, while the International System had 1.25, 1.25 and $1.75 \mathrm{~mm}$. The actual form at the root was left to the manufacturer.

Another important screw thread system used in Continental Europe was originally adopted in 1888 by the Verein Deutscher Ingenieure, and included screws of 6 to $40 \mathrm{~mm}$. diameter inclusive. The thread selected had an angle of $53^{\circ} 8^{\prime \prime}$, and was flattened at the top and bottom $1 / 8$ the height of the basic triangle, which naturally had a height equal to its base, therefore making a depth of thread $3 / 4$ the pitch. In 1893 a commission representing German instrument makers, technical societies and government departments adopted a system of threads ranging in diameter from $1 \mathrm{~mm}$. to $10 \mathrm{~mm}$., and especially intended for use in small machines and instruments. The same form of thread was employed as in the earlier system, and the overlapping sizes from $6 \mathrm{~mm}$. to $10 \mathrm{~mm}$. were identical. This system was called the Loewenherz System, after Dr. Leopold Loewenherz, at one time Director of the Physicalisch-Technischen-Reichs-Anstalt.

It will be apparent, therefore, that irrespective of the fundamental system of linear measures used, whether Anglo-Saxon or Metric, there wais and is throughout the world a great diversity of threads, and this was distinctly apparent in the war in the manufacture of ordnance, especially when three countries with different mechanical practice and standards such as Great Britain, France and the United States were concerned in the common manufacture and use of ordnance matériel. In France various systems had been used even within the army, and it was decided during the war to adopt a standard artillery system of screw threads which was based in the main on the International system, modified, however, as was appropriate for ordnance. In the meantime much of the material had been made with various threads, including the Loewenherz Thread, and matériel made in the United States designed to be interchangeable with the French also employed the Loewenherz Thread, for which various gages were sent from France to America.

But aside from matters of war material, manufacturers and authorities in the United States and Great Britain, France, and other foreign countries, have been keenly alive to the industrial and commercial situation involved, and during the past year there has been considerable progress made toward international screw thread standardization, though little that is definite or actually accomplished can be recorded now. There have been numerous conferences between American and other national engineering commissions in regard to screw threads and pipe threads. In the opinion of the United States National Screw Thread Commission, which was established by Act of Congress approved July 18, 1918, and continued by a similar Act approved March 3, 1919, to ascertain and establish standards of screw threads for use of the Federal Government and in manufactures, such an international standard should be established by giving consideration to the predominating sizes and standards used in manufactured products, as well as to the possibilities of providing a means for producing this international screw thread by the use of either the English or the Metric System of measurement.

From the foregoing resume the main points and the divergencies of the various screw threads can be appreciated, and it would not seem difficult to develop a common international system upon which the manufacturing countries could unite at least so far as goods or materials intended for foreign trade are concerned, which system at least could be specified when desired. While important work has been done lately for various national screw thread systems the undertaking will not be complete until one absolutely international standard is secured with proper definition and tolerances, so that with taps, dies, and lead screws arranged on an interchangeable basis all screw products could be reduced to a single system the world over.

\section{ANTI-FRICTION NUT AND SCREW GEARING.*}

THE efficient cooling and lubricating of a long run of gearing is often overlooked until certain difficulties arise as to its running efficiency. An improved means of interest has recently been patented by Mr. F. L. Rapson, of Liverpool (patent specification, 131,475). It relates to anti-friction nut and screw gearing and particularly to gearing of the type in which a shaft or rod and a nut or block are formed with co-operating helical grooves for the reception of balls or rollers, which are circulated and returned externally of the block or nut.

As shown, a shaft or $\operatorname{rod} a$ is formed with an externnal helical semi-circular groove $b$ and a nut or sleeve $c$, which is adapted to be slipped on the rod, is formed with a similar internal helical groove $d$. Within these coöperating opposed grooves $b$ and $d$ is disposed a number of anti-friction rollers or balls $e$ to form an anti-friotion helical screw thread so

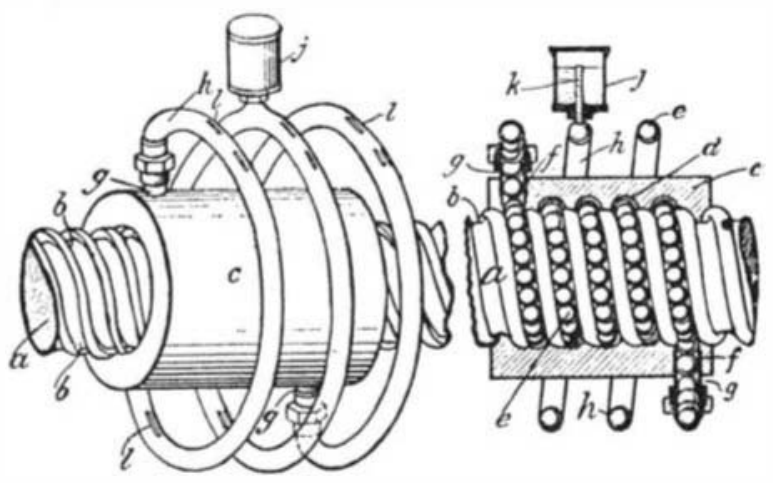

ANTI-FRICTION NUT AND SCREW GEARING

that when, for instance, the shaft $\boldsymbol{a}$ is rotated in one direction or the other without longitudinal movement, the block or the like $c$ is caused freely to move longitudinally thereon without friotion. Adjacent to each end of the block $c$ and at opposite sides thereof is drilled a hole $f$, which extends into the groove $d$. Within each of the pair of holes $f$ is inserted or screwed a short tube or pipe $g$ of sufficient diameter or size to allow the rollers or balls $e$ to pass freely therethrough. These two short tubes $g$ of the ball race are connected together by another tube $\boldsymbol{h}$, which is wound spirally around and externally of the block or nut c. This spiral tube $\boldsymbol{h}$ is connected to the shorter tubes by unions or other suitable detachable means $i$. Midway between the ends of the spiral tube $\boldsymbol{h}$ is provided a lubricator $j$, having a wick $k$ which is adapted to wipe the rollers or balls $e$ during their movement through the spiral circulating tube $\boldsymbol{h}$. This tube $\boldsymbol{h}$ is also provided at the upper side with a number of openings $l$ for the admission of air to cool the roller or balls $e$ during their circulation through the tube $\boldsymbol{h}$.

In operation, the rollers or balls $e$, which are arranged in close contact in the cooperating grooves $b$ and $d$ between the stops or pipes $f$ and in the spiral communicating pipe $\boldsymbol{h}$, will be carried along the block $c$ as the shaft or rod $a$ is rotated, and will pass through the pipe $\boldsymbol{h}$ and be efficiently cooled and lubricated. 